\title{
The faster the better? Time to first CT scan after admission in moderate-to-severe traumatic brain injury and its association with mortality
}

\author{
Marius Marc-Daniel Mader ${ }^{1} \cdot$ Roman Rotermund $^{1} \cdot$ Rolf Lefering $^{2} \cdot$ Manfred Westphal $^{1} \cdot$ Marc Maegele $^{2,3}$. \\ Patrick Czorlich ${ }^{1}$ (D) t the TraumaRegister DGU ${ }^{4}$
}

Received: 1 September 2020 / Revised: 18 November 2020 / Accepted: 7 December 2020 / Published online: 18 December 2020

(C) The Author(s) 2020

\begin{abstract}
Fast acquisition of a first computed tomography (CT) scan after traumatic brain injury (TBI) is recommended. This study is aimed at investigating whether the length of the period preceding initial CT scan influences mortality in patients with leading TBI. A retrospective cohort analysis of patients registered in the TraumaRegister DGU® was conducted including adult patients with TBI, defined as Abbreviated Injury Scale $_{\text {Head }} \geq 3$ and GCS $\leq 13$ who had been treated in level 1 or 2 trauma centers from $2007-$ 2016. Patients were grouped according to time intervals either from trauma or from admission to CT. A total of 6904 patients met the inclusion criteria. Mean time period from trauma to hospital admission was 68.8 min. From admission to first CT, a mean of 19.0 min elapsed. Trauma severity was higher in groups with a longer duration from trauma to CT as represented by a mean ( \pm standard deviation) Injury Severity Score (ISS) of 19.8 $\pm 9.0,20.7 \pm 9.3$, and $21.4 \pm 7.5$ and similar distribution of mortality of $24.9 \%, 29.9 \%$, and $36.3 \%$ in the $\leq 60-\mathrm{min}, 61-120-\mathrm{min}$, and $\geq 121-\mathrm{min}$ groups, respectively. An adjusted multivariable logistic regression model showed a significant influence of the level of the trauma center $(p=0.037)$ but not for interval from admission to CT $(p=0.528)$. TBI patients with a longer time span from trauma to first CT were more severely injured and demonstrated a worse prognosis, but received a CT scan faster when duration from admission is observed. The duration until the CT scan was obtained showed no significant impact on the mortality.
\end{abstract}

Keywords Traumatic brain injury $\cdot$ Trauma $\cdot$ Register $\cdot$ Computed tomography $\cdot$ Mortality $\cdot$ Admission

\section{Introduction}

Despite the efforts taken to improve care and outcome of patients suffering from traumatic brain injury (TBI), the burden of TBI is still associated with large medical and socioeconomic problems $[15,19]$. A recent publication of the

Patrick Czorlich

p.czorlich@uke.de

1 Department of Neurosurgery, University Medical Center Hamburg-Eppendorf, Martinistr. 52, 20246 Hamburg, Germany

2 Institute of Research in Operative Medicine (IFOM), University Witten/Herdecke, Cologne, Germany

3 Department for Trauma and Orthopedic Surgery, Cologne-Merheim Medical Center, University Witten/Herdecke, Cologne, Germany

4 Committee on Emergency Medicine, Intensive Care and Trauma Management (Sektion NIS) of the German Trauma Society (DGU), Berlin, Germany
TraumaRegister DGU® (TR-DGU) reported a rate of app. 8220 cases per year with an incidence of $10.1 / 100,000 /$ year for a moderate or severe TBI in Germany between 2013 and 2017 [15]. To confirm a clinically suspected TBI, it is deemed necessary to carry out an imaging diagnostic, in most cases a computed tomography (CT), which represents the "gold standard" [18]. This fact is reflected by the CENTER-TBI consortium that regards a 24/7 availability of CT scan and radiologist review as a quality indicator in the treatment of TBI patients [10]. Timely access to computed tomography (CT) has been defined as a major prerequisite for the participation of trauma centers within the TraumaNetzwerk DGU® [3]. These recommendations are mainly based on a landmark publication by Huber-Wagner et al. in 2009 demonstrating that the integration of a whole-body CT into early trauma care significantly reduced the mortality [8]. In an Austrian multi-center study, the authors recommend to perform the first CT scan within 20-30-min upon arrival [2]. Duration from admission to CT scan was shown to be associated with the localization of the 
CT scanner in close relation to the trauma room which had also a beneficial effect on mortality [9]. The REACT-I trial also demonstrated a significant reduction of the duration with the CT localized in the trauma room but without an effect on outcome which is similar to another study $[18,20]$. Overall, not only is the data on the duration from admission to the first CT scan in TBI patients sparse but also is the impact of the duration on mortality rarely evaluated in detail $[2,4,12,15$, $16,19]$.

The aim of this retrospective multi-center analysis based on prospectively collected data from the TR-DGU was to investigate the impact of the duration from admission to first cranial computed tomography and its association with in-house mortality.

\section{Material and methods}

\section{TraumaRegister DGU ${ }^{\circledR}$}

The TR-DGU was founded in 1993. The aim of this multicenter database is a pseudonymized and standardized documentation of severely injured patients. Data are collected prospectively in four consecutive time phases from the site of the accident until discharge from hospital: (A) prehospital phase, (B) emergency room (ER) and initial surgery, (C) intensive care unit (ICU), and (D) discharge. The documentation includes detailed information on demographics, injury pattern, comorbidities, pre- and in-hospital management, ICU course, and relevant laboratory findings including data on transfusion and outcome of each individual. The inclusion criterion is admission to hospital via the emergency room with vital signs and subsequent transfer to the ICU or intermediate care unit or death before admission to the ICU.

The infrastructure for documentation, data management, and data analysis is provided by the AUC (Academy for Trauma Surgery), a company affiliated to the German Trauma Society. The scientific leadership is provided by the Committee on Emergency Medicine, Intensive Care and Trauma Management (Sektion NIS) of the German Trauma Society. The participating hospitals submit their pseudonymized data into a central database via a web-based application. Scientific data analysis is approved according to a peer review procedure established by Sektion NIS.

The participating hospitals are primarily located in Germany (90\%), but a rising number of hospitals of other countries contribute data as well. Currently, approximately 33,000 cases from over 650 hospitals are entered into the database per year. Participation in the TR-DGU is voluntary. For hospitals associated with TraumaNetzwerk DGUß, however, the entry of at least a basic data set is obligatory for reasons of quality assurance. The basic data set is mostly provided by smaller hospitals and contains only a limited range of variables, e.g., no surgical procedures and no times from admission to CT which was analyzed in this study. The standard data set with more detailed information is mostly submitted by high-level trauma centers.

The present study is in line with the publication guidelines of the TraumaRegister DGUß and registered as TR-DGU project ID 2018-004. Furthermore, it was reported to the local ethic committee (WF-059-18).

\section{Study cohort and variables}

Although the TR-DGU database comprises a wide variety of information for each case, only patients $\geq 16$ years of age treated in participating German level I and II hospitals between 2007 and 2016 with a predominating moderate-tosevere TBI (defined as an Abbreviated Injury Scale (AIS) of the head score $\geq 3$ and an AIS in any other body $\leq 2$ ) and a Glasgow Coma Scale $(\mathrm{GCS}) \leq 13)$ were potentially eligible for the analysis. Patients documented only with the basic data set were excluded as the basic data set does not include information on CT times. Patients who were early $(<48 \mathrm{~h})$ transferred to a different hospital were not considered because no outcome information for these patients is available in the TRDGU database. Missing data of the GCS or pupil status were also an exclusion criterion as well as patients with no CT or a missing time value. The selection process is described in detail in Fig. 1.

Primary outcome parameter in this analysis was the inhouse mortality.

Variables extracted from the TR-DGU included basic demographic data, trauma mechanism, and American Society of Anesthesiologists (ASA) physical status classification. Parameters of trauma severity were Injury Severity Score (ISS), AIS of different body regions, and the Revised Injury Severity Classification, version II (RISC-II) predicting the risk of death as discussed by Baker et al. [1, 14]. The RISC-II score has been validated for mortality prediction depending on the clinical status in the emergency room of a large number of patients included into the TR-DGU data set [14]. It considers the AIS severity levels of both worst and second-worst injuries and head injury as well as the variables age, sex, pupil reactivity, and size; preinjury health status; blood pressure; acidosis; coagulation; hemoglobin; and cardiopulmonary resuscitation (CPR). The RISC-II score (higher value means better survival) is transformed into a risk of death estimator using the logistic function.

Additional variables extracted included GCS, rate of whole-body CT, rate of abdominal sonography and chest Xray in the trauma room, time from trauma to hospital, and total time in the trauma room. For evaluation of time to CT, two variables were calculated: "time from trauma to first $\mathrm{CT}$ " included preclinical and trauma room management whereas 


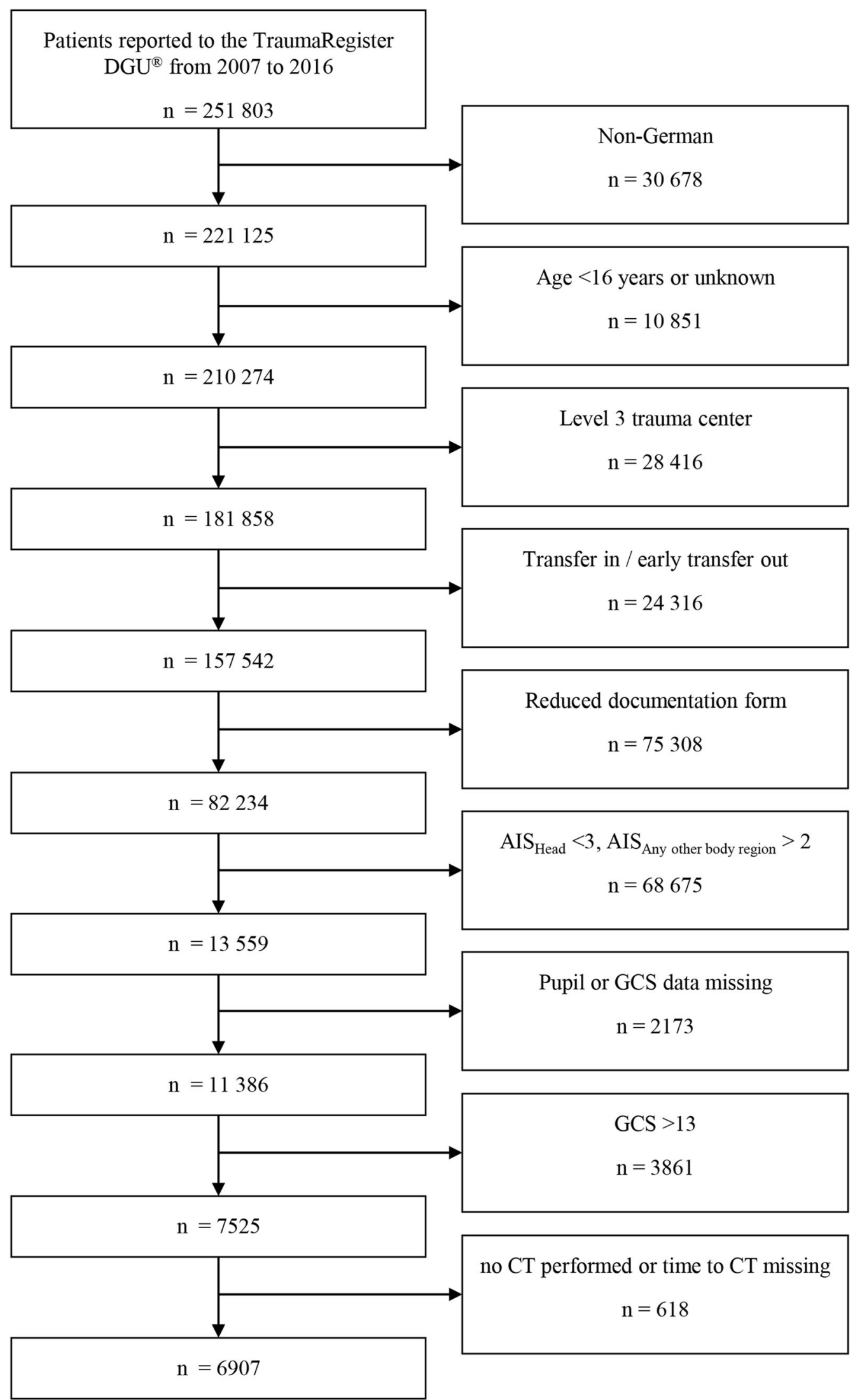

Fig. 1 The flowchart describes the exclusion and inclusion criteria. AIS Abbreviated Injury Scale, CT computed tomography, DGU German Trauma Society (Deutsche Gesellschaft für Unfallchirurgie), GCS Glasgow Coma Scale 
"time from admission to first $\mathrm{CT}$ " only considered the timeframe within the hospital until CT.

\section{Statistical methods}

Statistical analyses were performed using SPSS statistical software (SPSS Version 24.0, IBM Inc., Armonk, New York, USA). Data are presented as mean \pm standard deviation (SD) for continuous variables and as numbers and/or percentages for categorical variables respectively as median and interquartile range (IOR). Values of times from trauma to admission, respectively, trauma to first $\mathrm{CT}$ and admission to first $\mathrm{CT}$ are presented in both mean $\pm \mathrm{SD}$ and median plus IQR to compare the results with the literature.

In order to assess the impact of the different mentioned time spans on mortality, standardized mortality ratios (SMR) and corresponding $95 \%$ confidence intervals (CI) were calculated using the RISC-II score to compare the observed mortality with the expected mortality. Finally, a multivariable logistic regression analysis was performed to assess the independent impact of the trauma center level and time from admission to the CT scan on mortality. The model was adjusted for the RISC-II score. Results were presented as odds ratios (OR) with corresponding 95\%CI.

\section{Results}

In accordance with the selection process shown in Fig. 1, 6907 patients met the inclusion criteria. The study cohort showed a male predominance (66.4\%) and a mean age of 58.1 (SD 21.7) years. The most frequent trauma mechanism was low fall from less than $3 \mathrm{~m}$. Mean ISS was 20.7. TBI was critical (AIS 5) or maximal (AIS 6) in $42.4 \%$ of patients. Anisocoric or bilaterally dilated pupils were present in $32.8 \%$ of patients. Mean time period from trauma to hospital admission was $68.8 \mathrm{~min}$. From admission to first CT, a mean of 19.0 min elapsed. This time period was shorter in level 1 trauma centers. Mortality was $31.7 \%$ with early mortality within $24 \mathrm{~h}$ accounting for almost half of fatalities. A detailed description of the study cohort is provided in Table 1.

Table 2 depicts subgroups of the study cohort dependent on different timeframes from admission to CT. Most cases demonstrated a time period of 11 to $20 \min (44.9 \%)$ whereas a period of more than $30 \mathrm{~min}$ was present in only $11.3 \%$ of cases (Fig. 2). Trauma appeared slightly more severe in groups with shorter timeframes: mean ISS was 21.3 and 20.2, median GCS was 6 and 8 and mean age of years was 56.8 and 60.1 in the $\leq$ 10 -min and $\geq 31$-min groups, respectively. Patients of the $\leq$ 10-min group received the lowest rate of additional imaging like abdominal sonography ( $64.2 \%$ vs. $81.6 \%$ overall) or chest X-ray ( $21.0 \%$ vs. $40.5 \%$ overall). Mortality was the highest in the $\leq 10$-min group (32.4\%) and the lowest in the $\geq 31$-min group (30.0\%). The distribution of pupil status changed steadily over the length of the timeframe from $63.2 \%$, $21.2 \%$, and $15.7 \%$ in the $\leq 10-\min$ group to $76.6 \%, 13.9 \%$, and $9.5 \%$ in the $\geq 31$-min group for normal, anisocoric, and bilaterally dilated pupils, respectively. Overall, the time from the admission to the execution of the CT examination in level 1 centers was faster than in level 2 centers (Fig. 3).

In 5259 of 6907 patient $(76.1 \%)$ data were available for timeframe from trauma to initial CT. The average duration from trauma to initial CT was $87.4 \pm 33$ min with a duration between 61 and $120 \mathrm{~min}$ for $67.8 \%$ of the patients. A CT scan within an hour from trauma was performed in $19.5 \%$ of patients whereas a time period of more than $2 \mathrm{~h}$ was present in $12.7 \%$ of cases. Table 3 depicts the characteristics of these subgroups. Trauma severity and age were higher in groups with a longer timeframe. Mean ISS was $19.8 \pm 9.0,20.7 \pm$ 9.3, and $21.4 \pm 7.5$ in the $\leq 60$-min, 61-120-min, and $\geq 121$ min groups, respectively. Equally, median GCS was the highest in the $\leq 60$-min group (9 IQR 4-12) and the lowest in the $\geq 121$-min group (6 IQR 3-10). Mortality exhibited a similar distribution of $24.9 \%, 29.9 \%$, and $36.3 \%$ in the $\leq 60$ min, 61-120-min, and $\geq 121$-min groups, respectively, and is also depicted in Fig. 4. In contrast to the faster times between admission of the patient and performing the CT between the levels of the trauma centers, there was no relevant difference between the times from accident to CT (Fig. 3).

To explore the influence of CT timing on mortality, SMRs were calculated (Table 4 and Fig. 4). Generally, the observed mortality of the overall cohort $(31.7 \%)$ was higher than the predicted mortality according to RISC-II (29.3\%, Table 1$)$. With regards to time period from admission to $\mathrm{CT}$, a mortality ratio higher than expected was present in the 11-20-min (1.11, $95 \%$ CI $1.05-1.17)$ and the $\geq 31$-min group $(1.13,95 \%$ CI 1.00 1.25). The groups of $\leq 60 \mathrm{~min}$ and $61-120 \mathrm{~min}$ from trauma to CT also showed elevated mortality ratios of 1.14 (95\%CI 1.011.26 ) and 1.08 (95\% CI 1.02-1.13), respectively.

Finally, the multivariable logistic regression analysis demonstrated that treatment at a level 2 trauma center was associated with slightly but statistically significant increased mortality risk (odds ratio (OR) 1.280; CI 1.015-1.614). Again, time from admission to CT had no significant impact in this model (OR 1.002; CI 0.996-1.008) (Table 5).

\section{Discussion}

The need for a rapid CT scan to determine a traumatic brain injury as part of the trauma management is obvious. A 24/7 availability of a CT scan with radiological assessment is required. This should be performed within 20-30 min after admission of the patient in order to be able to provide early surgical therapy in case of intracranial hematoma to lower 
Table 1 Demographic, clinical, and outcome data of patients

\begin{tabular}{|c|c|c|c|}
\hline \multirow[t]{35}{*}{ Demographics and clinical data } & Sex & Female & $2309(33.4 \%)$ \\
\hline & Age & Mean $\pm \mathrm{SD}$ (years) & $58.1 \pm 21.7$ \\
\hline & Trauma mechanism & TA car & $599(8.7 \%)$ \\
\hline & & TA motorcycle & $266(3.9 \%)$ \\
\hline & & TA bicycle & $809(11.7 \%)$ \\
\hline & & TA pedestrian & $398(5.8 \%)$ \\
\hline & & Fall $>3 \mathrm{~m}$ & $759(11.0 \%)$ \\
\hline & & Fall $<3 \mathrm{~m}$ & $2984(43.2 \%)$ \\
\hline & & Other & $918(13.3 \%)$ \\
\hline & Trauma type & Blunt & $6378(92.4 \%)$ \\
\hline & ISS & Mean \pm SD & $20.7 \pm 9.1$ \\
\hline & TBI characteristics & Epidural hematoma & $708(10.3 \%)$ \\
\hline & & Subdural hematoma & $3475(50.3 \%)$ \\
\hline & & Subarachnoid hemorrhage & $2424(35.1 \%)$ \\
\hline & & Intracerebral hemorrhage & $4077(59.0 \%)$ \\
\hline & & Edema/swelling & $1118(16.2 \%)$ \\
\hline & & Brainstem hemorrhage & $392(5.7 \%)$ \\
\hline & & Skull fractures & $3602(52.1 \%)$ \\
\hline & AIS head & 3 & $1973(28.6 \%)$ \\
\hline & & 4 & $2006(29.1 \%)$ \\
\hline & & 5 & $2840(41.1 \%)$ \\
\hline & & 6 & $85(1.2 \%)$ \\
\hline & GCS & Median (IQR) & $7(3-11)$ \\
\hline & Motor response & Normal & $665(9.6 \%)$ \\
\hline & & Specific & $2980(43.2 \%)$ \\
\hline & & Nonspecific & $931(13.5 \%)$ \\
\hline & & None & $2328(33.7 \%)$ \\
\hline & Pupil reactivity & Brisk & $3343(48.4 \%)$ \\
\hline & & Sluggish & $2058(29.8 \%)$ \\
\hline & & Fixed & $1506(21.8 \%)$ \\
\hline & Pupil size & Normal & $4640(67.2 \%)$ \\
\hline & & Anisocoric & $1331(19.3 \%)$ \\
\hline & & Bilaterally dilated & $933(13.5 \%)$ \\
\hline & Reanimation & Present & $94(1.4 \%)$ \\
\hline & MSCT & Present & $5056(73.2 \%)$ \\
\hline \multirow[t]{5}{*}{ Timing } & Time from admission to first $\mathrm{CT}$ & Mean $\pm \mathrm{SD}(\min )$ & $19.0 \pm 12.2$ \\
\hline & - Level 1 trauma center & Mean $\pm \mathrm{SD}(\min )$ & $18.7 \pm 11.8$ \\
\hline & - Level 2 trauma center & Mean $\pm \mathrm{SD}(\min )$ & $21.5 \pm 14.7$ \\
\hline & Time from trauma to hospital & Mean $\pm \mathrm{SD}(\min )$ & $68.8 \pm 31.1$ \\
\hline & Total time in trauma room & Mean $\pm \mathrm{SD}(\min )$ & $52.0 \pm 31.6$ \\
\hline \multirow[t]{5}{*}{ Outcome } & Predicted mortality (RISCII) & Mean \pm SD $(\%)$ & $29.3 \pm 32.2$ \\
\hline & Mortality & Total & $2187(31.7 \%)$ \\
\hline & & within $24 \mathrm{~h}$ & $1005(14.6 \%)$ \\
\hline & & within $6 \mathrm{~h}$ & $347(5.0 \%)$ \\
\hline & Length of stay in hospital & Mean \pm SD (days) & $15.0 \pm 15.0$ \\
\hline
\end{tabular}

AIS Abbreviated Injury Scale, CT computed tomography, GCS Glasgow Coma Scale; ISS Injury Severity Score, IQR interquartile range, MSCT multislice computed tomography indicating whole-body CT, RISC-II Revised Injury Severity Classification II, SD standard deviation, TA traffic accident 
Table 2 Demographic, clinical, and outcome data of patients distributed of time from admission of the patient to first CT in minutes. Time of trauma to hospital was available for 5259 patients $(76.1 \%)$

\begin{tabular}{|c|c|c|c|c|c|c|}
\hline & & \multicolumn{3}{|c|}{ Time from admission to first $\mathrm{CT}$ (min) } & \multirow[b]{2}{*}{$\geq 31$} & \multirow[b]{2}{*}{ Total } \\
\hline & & $\leq 10$ & $11-20$ & $21-30$ & & \\
\hline Total & & $1539(22.3 \%)$ & $3106(45.0 \%)$ & $1483(21.5 \%)$ & $779(11.3 \%)$ & 6907 \\
\hline Age & Mean $\pm \mathrm{SD}$ (years) & $56.8 \pm 21.7$ & $58.1 \pm 21.7$ & $58.6 \pm 21.6$ & $60.1 \pm 21.5$ & $58.1 \pm 21.7$ \\
\hline ISS & Mean \pm SD & $21.3 \pm 9.7$ & $20.6 \pm 9.1$ & $20.5 \pm 9.0$ & $20.2 \pm 8.5$ & $20.7 \pm 9.1$ \\
\hline AIS head & 5 and 6 & $696(45.2 \%)$ & $1303(42.0 \%)$ & $631(42.5 \%)$ & $296(38.0 \%)$ & $2924(42.4 \%)$ \\
\hline GCS & $\leq 8$ & $973(64.4 \%)$ & $1891(62.0 \%)$ & $852(59.1 \%)$ & $390(52.8 \%)$ & $4102(60.9 \%)$ \\
\hline Pupils bilaterally dilated & Present & $241(15.7 \%)$ & $430(13.9 \%)$ & $188(12.7 \%)$ & $74(9.5 \%)$ & $933(13.5 \%)$ \\
\hline Systolic blood pressure & Mean $\pm \mathrm{SD}(\mathrm{mmHg})$ & $138.0 \pm 38.7$ & $138.7 \pm 39.3$ & $137.6 \pm 39.9$ & $137.4 \pm 38.2$ & $138.2 \pm 39.2$ \\
\hline Abdominal sonography & Present & $987(64.2 \%)$ & $2696(86.8 \%)$ & $1311(88.4 \%)$ & $643(82.5 \%)$ & $5632(81.6 \%)$ \\
\hline Chest X-ray & Present & $323(21.0 \%)$ & $1237(39.8 \%)$ & $795(53.6 \%)$ & $443(56.9 \%)$ & $2794(40.5 \%)$ \\
\hline Reanimation & Present & $19(1.3 \%)$ & $39(1.3 \%)$ & $21(1.4 \%)$ & $15(2.0 \%)$ & $94(1.4 \%)$ \\
\hline Time: trauma to hospital & Mean $\pm \mathrm{SD}(\min )$ & $70.8 \pm 32.3$ & $69.1 \pm 31.3$ & $67.7 \pm 29.2$ & $65.5 \pm 30.8$ & $68.8 \pm 31.1$ \\
\hline Time: admission to first CT & Mean $\pm \mathrm{SD}(\min )$ & $7.5 \pm 2.5$ & $15.5 \pm 2.9$ & $25.0 \pm 2.8$ & $43.7 \pm 16.3$ & $19.0 \pm 12.2$ \\
\hline Mortality & Present & $497(32.3 \%)$ & $1001(32.2 \%)$ & $455(30.7 \%)$ & $234(30.0 \%)$ & $2186(31.7 \%)$ \\
\hline Length of stay in hospital & Mean \pm SD (days) & $14.9 \pm 13.8$ & $14.7 \pm 15.5$ & $15.0 \pm 14.2$ & $16.3 \pm 16.4$ & $15.0 \pm 15.0$ \\
\hline
\end{tabular}

AIS Abbreviated Injury Scale, $C T$ computed tomography, GCS Glasgow Coma Scale, IQR interquartile range, ISS Injury Severity Score, SD standard deviation

intracranial pressure and minimize secondary brain damages $[2,10,17]$.

Surprisingly, very little data has been published on this topic so far, making this study driven from the TR-DGU one of the largest investigations of the impact of the duration from admission to first computer tomography scan in moderate-tosevere traumatic brain injury.

Timeframes from trauma and from admission to the CT scan were 87.4 and $19.0 \mathrm{~min}$ in our study cohort, respectively, which appears short in comparison with other studies $[2,4,12$, $15,16,19]$.
Overall, however, the comparability of the results is only possible to a very limited extent, since the studies differ in the composition of the cohort, which is apparent from different ISS. Moreover, some studies showed marked variation in the rate of abdominal ultrasound examinations and chest X-ray examinations. Accordingly, with an increased rate of additional diagnostic measures, the average time taken to perform the CT scan was longer [9, 18]. This fact is also evident in our study, as time to CT increased with an increase in the rate of additional examinations.

Another factor influencing the time between admission and first CT scan could be the proximity of the CT to the

Fig. 2 Distribution of times from admission of the patient until the CT scan. CT computed tomography

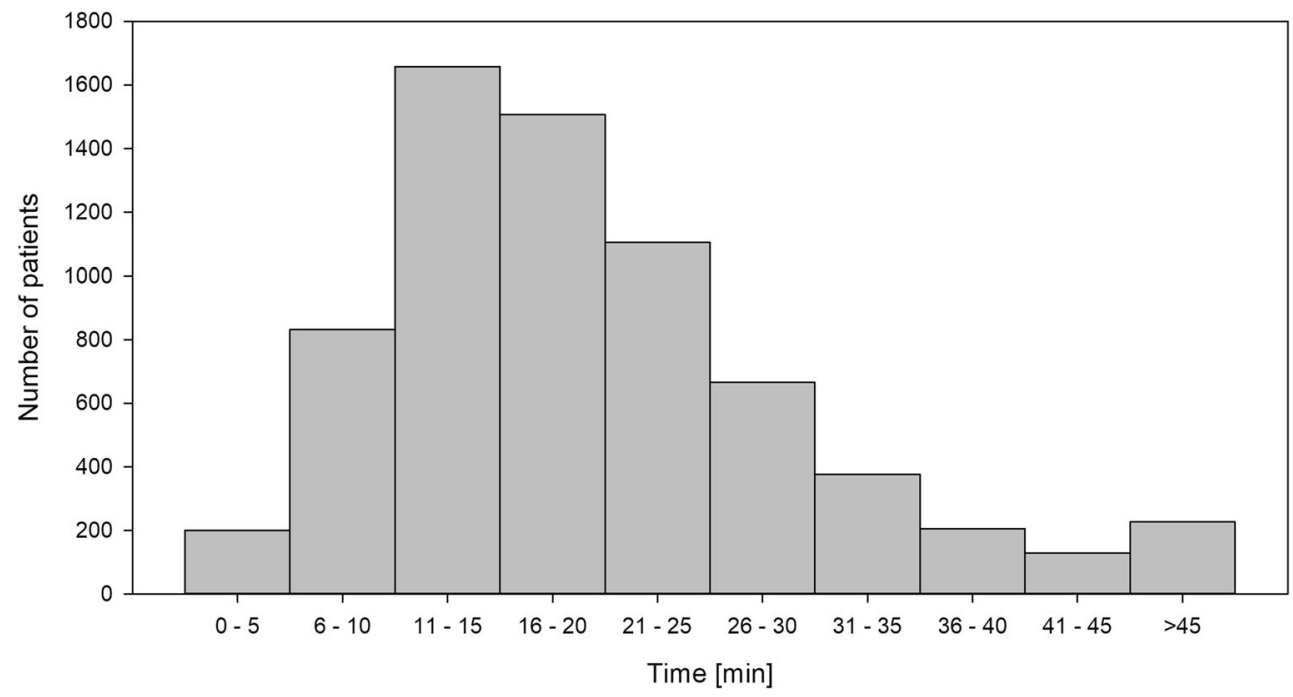


Fig. 3 Line plot of times from admission and from trauma to CT in level 1 and 2 trauma centers. CT computed tomography

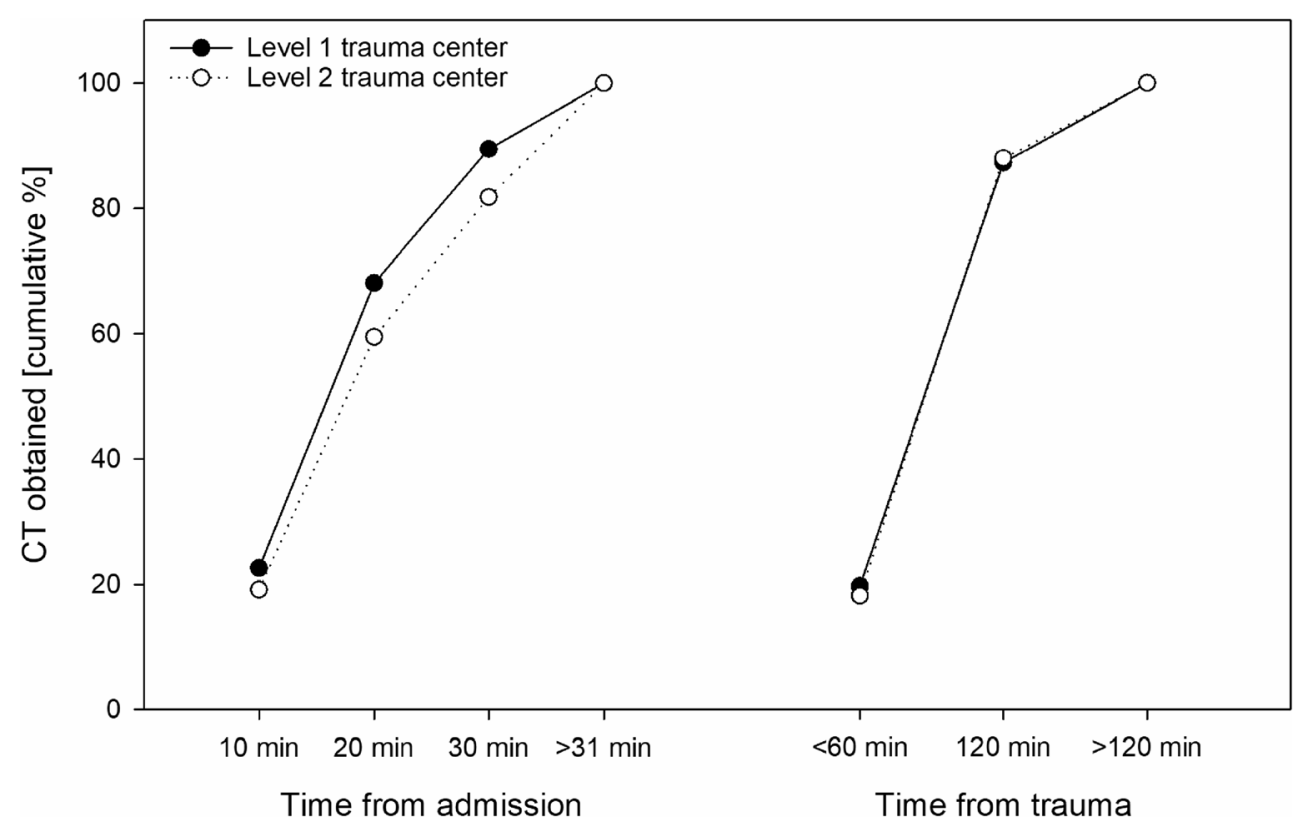

trauma room. However, results of studies addressing this issue are divergent. The REACT-1 study demonstrated that a CT scanner located in the trauma room reduced the duration ( 24 vs. $38 \mathrm{~min}$ ) until the first imaging but was not associated with statistically significant beneficial outcome in severe TBI patients [18]. In contrast, Huber-Wagner et al. observed that the location of a CT scanner in the trauma room was associated with a mean reduction of $5 \mathrm{~min}$ (17.1 vs. $22.7 \mathrm{~min}$ ) compared to a CT equal or less than $50 \mathrm{~m}$ away and was associated with a reduction of the observed mortality [9]. Surprisingly, not only the associated outcome but also the timing of the $\mathrm{CT}$ scan itself is reported heterogeneously in further studies evaluating the positioning of a CT scanner in the trauma room [7, 13]. In a prospective single-center study, time spans were compared before and after installation of a new CT scanner demonstrating a minimal prolongation in the new setting ( 20 vs. $21 \mathrm{~min}$ ) [20]. In contrast, the installation of a hybrid emergency room at another institution was associated with shorter times to the first imaging ( 25 vs. $14 \mathrm{~min}$ ), earlier initiation of emergency surgery, and improved functional outcome in patients with severe TBI [11]. These different

Table 3 Demographic, clinical, and outcome data of patients distributed of time from trauma of the patient to first CT in minutes. Time of trauma to hospital was available for 5259 patients (76.1\%)

\begin{tabular}{|c|c|c|c|c|c|}
\hline & & \multicolumn{3}{|c|}{ Time from trauma to first $\mathrm{CT}(\mathrm{min})$} & \multirow[b]{2}{*}{ Total } \\
\hline & & $\leq 60$ & $61-120$ & $\geq 121$ & \\
\hline Total & & $1027(19.5 \%)$ & $3566(67.8 \%)$ & $666(12.7 \%)$ & 5259 \\
\hline Age & Mean $\pm \mathrm{SD}$ (years) & $54.8 \pm 21.3$ & $57.0 \pm 21.9$ & $61.2 \pm 20.9$ & $57.1 \pm 21.8$ \\
\hline ISS & Mean \pm SD & $19.8 \pm 9.0$ & $20.7 \pm 9.3$ & $21.4 \pm 7.5$ & $20.6 \pm 9.0$ \\
\hline AIS head & 5 and 6 & $356(34.7 \%)$ & $1443(40.5 \%)$ & $329(49.4 \%)$ & $2128(40.5 \%)$ \\
\hline GCS & $\leq 8$ & $493(49.5 \%)$ & $2135(61.1 \%)$ & $438(66.8 \%)$ & $3066(59.6 \%)$ \\
\hline Systolic blood pressure & Mean $\pm \mathrm{SD}(\mathrm{mmHg})$ & $137.8 \pm 36.1$ & $136.8 \pm 38.9$ & $139.3 \pm 42.0$ & $137.3 \pm 38.8$ \\
\hline Abdominal sonography & Present & $798(77.8 \%)$ & $2930(82.2 \%)$ & $548(82.3 \%)$ & $4276(81.4 \%)$ \\
\hline Chest X-ray & Present & $354(34.5 \%)$ & $1484(41.6 \%)$ & $288(43.2 \%)$ & $2126(40.4 \%)$ \\
\hline Reanimation & Present & $12(1.2 \%)$ & $46(1.3 \%)$ & $11(1.7 \%)$ & $69(1.3 \%)$ \\
\hline Time: trauma to hospital & Mean $\pm \mathrm{SD}(\min )$ & $37.2 \pm 9.2$ & $67.4 \pm 17.3$ & $125.0 \pm 34.8$ & $68.8 \pm 31.1$ \\
\hline Time: admission to first CT & Mean $\pm \mathrm{SD}(\min )$ & $13.2 \pm 6.4$ & $18.8 \pm 10.2$ & $26.1 \pm 20.6$ & $18.7 \pm 12.0$ \\
\hline Mortality & Present & $255(24.9 \%)$ & $1067(29.9 \%)$ & $242(36.3 \%)$ & $1564(29.8 \%)$ \\
\hline Length of stay in hospital & Mean \pm SD (days) & $14.3 \pm 11.9$ & $15.2 \pm 15.3$ & $15.7 \pm 15.0$ & $15.1 \pm 14.8$ \\
\hline
\end{tabular}

AIS Abbreviated Injury Scale, CT computed tomography, GCS Glasgow Coma Scale; ISS Injury Severity Score, SD standard deviation 
Fig. 4 Mortality (bar with 95\% confidence interval) and RISC-II prognosis (horizontal line) distributed on the time until the CT examination. RISC-II Revised Injury Severity Classification II

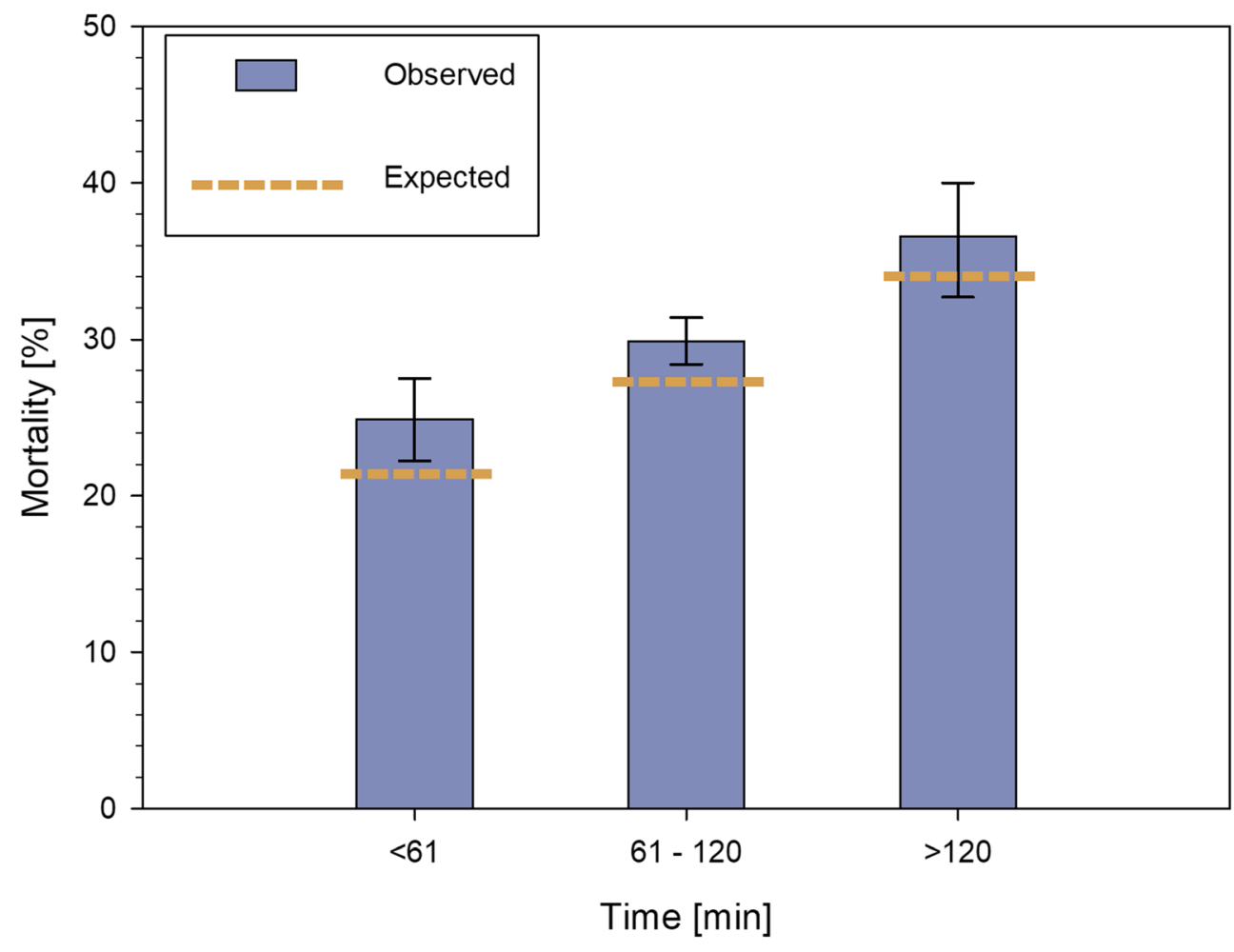

results suggest that in addition to the spatial distance of the CT scanner from the trauma room, local treatment algorithms seem to determine the time period before imaging [9]. As a consequence, the TraumaNetzwerk DGU® (trauma networks; TNW) and guidelines were introduced to standardize the treatment algorithms and to optimize the treatment level for trauma patients in Germany. High standards are requested from participating hospitals regarding personal, organization, and infrastructure. For example, immediate proximity of the trauma room to the radiology department is mandatory for level I trauma centers and proximity is recommended for level II centers [3]. The guideline also includes recommendations when to perform abdominal sonography or chest X-ray examinations in the trauma room. Depending on the suspected severity of trauma, this might result in a higher frequency of these diagnostic measures which is naturally also reflected in an extended time period until a CT scan is performed. However, we show that longer time spans do not lead to a significant increase of the SMR. This may be interpreted as support for implemented guidelines since delays in acquiring cerebral imaging seem to be justified and to serve the adequate management of the trauma patient. Another notable finding of the study is that emergency room staff obviously pays attention to the admission status of the pupils as the rate of patients with anisocoric or bilaterally fixed and dilated pupils was associated with faster acquisitions of the CT. Overall, adherence to guidelines and recommendations can demonstrably lead to an improvement in care in patients with TBI and offer the opportunity for quality improvements, especially in process management $[2,5,6,10]$.

Table 4 Observed versus predicted mortality using the RISC II and standardized mortality ratio

\begin{tabular}{|c|c|c|c|c|}
\hline & & Observed mortality (\%) & Predicted mortality based on RISC II (\%) & SMR $(95 \% \mathrm{CI})$ \\
\hline \multirow[t]{4}{*}{ Time from admission to first CT (min), $n=6907$} & $\leq 10$ & 32.4 & 31.2 & $1.04(0.96-1.11)$ \\
\hline & $11-20$ & 32.2 & 29.1 & $1.11(1.05-1.17)$ \\
\hline & $21-30$ & 30.7 & 29.1 & $1.05(0.97-1.14)$ \\
\hline & $\geq 31$ & 30.0 & 26.7 & $1.13(1.00-1.25)$ \\
\hline \multirow[t]{3}{*}{ Time from trauma to first CT (min), $n=5259$} & $\leq 60$ & 24.9 & 21.9 & $1.14(1.01-1.26$ \\
\hline & $61-120$ & 29.9 & 27.8 & $1.08(1.02-1.13)$ \\
\hline & $\geq 121$ & 36.3 & 34.5 & $1.05(0.95-1.16$ \\
\hline
\end{tabular}

$C T$ computed tomography, $C I$ confidence interval, RISC-II Revised Injury Severity Classification II, SMR standardized mortality ratio 
Table 5 Multivariate regression analysis for Level 2 trauma center treatment and time to CT from admission adjusted for the RISC

\begin{tabular}{|c|c|c|c|c|}
\hline Mortality & Coefficient & $p$ value & OR & $95 \% \mathrm{CI}$ \\
\hline RISC-II score & -0.973 & $<0.001$ & 0.378 & $0.361-0.396$ \\
\hline Level 2 trauma center & 0.247 & 0.037 & 1.280 & $1.015-1.614$ \\
\hline Time to CT from admission (min) & 0.002 & 0.528 & 1.002 & $0.996-1.008$ \\
\hline Constant & 0.143 & $<0.001$ & 0.30 & \\
\hline
\end{tabular}

$C T$ computed tomography, CI confidence interval, OR odds ratio, RISC-I, Revised Injury Severity Classification II

The strength of the study is, on the one hand, the relatively high number of cases and, on the other hand, the multicenter approach through the use of data from the TR-DGU which allows a uniform and standardized collection of time data. Moreover, compared to other studies, the inclusion and exclusion criteria available from the TR-DGU allowed for a relatively homogeneous patient population to be evaluated.

This fact leads directly to the limitations of the study, namely, that an analysis of individual hospital data sets is not meaningfully possible and possible differences between the local treatment algorithms could have been shown to have a statistically significant effect on mortality. Furthermore, the study has the well-known limitations of a retrospective analysis; despite the fact that the data sets are prospectively entered into the TR-DGU, the results demonstrate associations and no causalities as mentioned before [8,9]. A usual issue of large-scale databases is the risk of incomplete or incorrect data despite various electronic plausibility checks when entering online data, which may have affected the presented results. However, it should be emphasized that the data entry for the times of admission of the patient as well as the CT examination are clearly defined and standardized for the TR-DGU. Another limitation of the TR-DGU is the lack of detail with regard to the pathology of the TBI, so that no detailed statements, e.g., the extent of hemorrhages, are available and only a categorization based on the AIS can be made which is needed for the adjustment in the RISC-II score. Finally, the RISCII score has been validated for mortality prediction of a large number of patients. However, it is not validated for special subgroup analyses like TBI patients [14].

\section{Conclusion}

TBI patients exhibiting a longer time span from trauma to first $\mathrm{CT}$ were more severely injured and demonstrated a worse prognosis. Conversely, patients with more severe injuries received a CT scan faster once admitted to the hospital. Surprisingly, the time span from admission to the CT scan itself showed no significant impact on the mortality in this cohort of the TR-DGU. It might be concluded that time management of trauma patients with TBI as leading injury in outof-hospital and early clinical setting is adequate leading to timely initial diagnostic measures without causing harmful delay.

Authors' contributions MMM, MM, and PC: conception and design of the study; RL, MMM, and PC: acquisition of data; MMM, RR, RL, MM, and PC: analysis and interpretation of the data; MMM and PC: drafting of the article; RR, RL, MW, and MM: provided critical revision of the article. All authors provided final approval of the version submitted for publication.

Funding Open Access funding enabled and organized by Projekt DEAL.

Data availability All epidemiological data presented in this study were retrieved from the TraumaRegister DGU® of the German Trauma Society. The data that support the findings of this study are available from TraumaRegister DGU® but restrictions apply to the availability of these data, which were used under license for the current study, and so are not publicly available.

\section{Compliance with ethical standards}

Conflict of interest Rolf Lefering declares that his institution (IFOM) has an ongoing service agreement with AUC GmbH, the owner of the TraumaRegister DGU database, which includes statistical support for scientific analyses using registry data. All other authors declare that they have no conflicts of interest.

Ethics approval The study was reported to the local ethic committee, Ärztekammer Hamburg (WF-059-18).

Consent to participate Written informed consent is waived for this kind of study.

Consent for publication Not applicable

Code availability Not applicable

Open Access This article is licensed under a Creative Commons Attribution 4.0 International License, which permits use, sharing, adaptation, distribution and reproduction in any medium or format, as long as you give appropriate credit to the original author(s) and the source, provide a link to the Creative Commons licence, and indicate if changes were made. The images or other third party material in this article are included in the article's Creative Commons licence, unless indicated otherwise in a credit line to the material. If material is not included in the article's Creative Commons licence and your intended use is not permitted by statutory regulation or exceeds the permitted use, you will need to obtain permission directly from the copyright holder. To view a copy of this licence, visit http://creativecommons.org/licenses/by/4.0/. 


\section{References}

1. Baker SP, O'Neill B, Haddon W Jr, Long WB (1974) The injury severity score: a method for describing patients with multiple injuries and evaluating emergency care. J Trauma 14(3):187-196

2. Brazinova A, Majdan M, Leitgeb J, Trimmel H, Mauritz W (2015) Austrian Working Group on Improvement of Early TBI Care. Factors that may improve outcomes of early traumatic brain injury care: prospective multicenter study in Austria. Scand J Trauma Resusc Emerg Med 23:53. https://doi.org/10.1186/s13049-0150133-z

3. DGU Weißbuch Schwerverletztenversorgung, 3. Erweiterte Auflage 2019 (Vorabdruck) https:/www.dgu-online.de/fileadmin/ published_content/5.Qualitaet_und_Sicherheit/PDF/2019_DGU Weissbuch_Schwerverletztenversorgung_Vorabdruck.pdf [in German, accessed Mar 10 2020]

4. Fainardi E, Chieregato A, Antonelli V, Fagioli L, Servadei F (2004) Time course of CT evolution in traumatic subarachnoid haemorrhage: a study of 141 patients. Acta Neurochir 146(3):257-263. https://doi.org/10.1007/s00701-003-0207-y

5. Fakhry SM, Trask AL, Waller MA, Watts DD, IRTC Neurotrauma Task Force (2004) Management of brain-injured patients by an evidence-based medicine protocol improves outcomes and decreases hospital charges. J Trauma 56(3):492-500. https://doi.org/ 10.1097/01.ta.0000115650.07193.66

6. Fung Kon Jin PH, Penning N, Joosse P, Hijdra AHJ, Bouma GJ, Ponsen KJ, Goslings JC (2008) The effect of the introduction of the Amsterdam Trauma Workflow Concept on mortality and functional outcome of patients with severe traumatic brain injury. J Neurotrauma 25(8):1003-1009. https://doi.org/10.1089/neu.2007. 0463

7. Gross T, Messmer P, Amsler F, Füglistaler-Montali I, Zürcher M, Hügli RW, Regazzoni P, Jacob AL (2010) Impact of a multifunctional image-guided therapy suite on emergency multiple trauma care. Br J Surg 97(1):118-127. https://doi.org/10.1002/bjs.6842

8. Huber-Wagner S, Lefering R, Qvick LM, Körner M, Kay MV, Pfeifer KJ, Reiser M, Mutschler W, Kanz KG, Working Group on Polytrauma of the German Trauma Society (2009) Effect of whole-body CT during trauma resuscitation on survival: a retrospective, multicentre study. Lancet 373(9673):1455-1461. https:// doi.org/10.1016/S0140-6736(09)60232-4

9. Huber-Wagner S, Mand C, Ruchholtz S, Kühne CA, Holzapfel K, Kanz KG, van Griesven M, Biberthaler P, Lefering R, TraumaRegister DGU (2014) Effect of the localisation of the CT scanner during trauma resuscitation on survival - a retrospective, multicentre study. Injury 45(Suppl 3):S76-S82. https://doi.org/10. 1016/j.injury.2014.08.022

10. Huijben JA, Wiegers EJA, Ercole A, de Keizer NF, Maas AIR, Steyerberg EW et al (2020) Quality indicators for patients with traumatic brain injury in European intensive care units: a CENTER-TBI study. Crit Care 24(1):78. Published 2020 Mar 4. https://doi.org/10.1186/s13054-020-2791-0

11. Kinoshita T, Hayashi M, Yamakawa K, Watanabe A, Yoshimura J, Hamasaki T, Fujimi S (2018) Effect of the hybrid emergency room system on functional outcome in patients with severe traumatic brain injury. World Neurosurg 118:e792-e799. https://doi.org/10. 1016/j.wneu.2018.07.053

12. Kompanje EJ, Maas AI, Slieker FJ, Stocchetti N (2007) Ethical implications of time frames in a randomized controlled trial in acute severe traumatic brain injury. Prog Brain Res 161:243-250. https:// doi.org/10.1016/S0079-6123(06)61017-0

13. Lee KL, Graham CA, Lam JM, Yeung JH, Ahuja AT, Rainer TH (2009) Impact on trauma patient management of installing a computed tomography scanner in the emergency department. Injury 40(8):873-875. https://doi.org/10.1016/j.injury.2008.12.001

14. Lefering R, Huber-Wagner S, Nienaber U, Maegele M, Bouillon B (2014) Update of the trauma risk adjustment model of the TraumaRegister DGU: the Revised Injury Severity Classification, version II. Crit Care 18(5):476. https://doi.org/10.1186/s13054014-0476-2

15. Maegele M, Lefering R, Sakowitz O, Kopp MA, Schwab JM, Steudel WI, Unterberg A, Hoffmann R, Uhl E, Marzi I (2019) The incidence and management of moderate to severe head injury - a retrospective analysis of data from the Trauma Register of the German Trauma Society. Dtsch Arztebl Int 116:167-173. https:// doi.org/10.3238/arztebl.2019.0167

16. Nagesh M, Patel KR, Mishra A, Yeole U, Prabhuraj AR, Shukla D (2019) Role of repeat CT in mild to moderate head injury: an institutional study. Neurosurg Focus 47(5):E2. https://doi.org/10.3171/ 2019.8.FOCUS19527

17. Picetti E, Rossi S, Abu-Zidan FM, Ansaloni L, Armonda R, Baiocchi GL, Bala M, Balogh ZJ, Berardino M, Biffl WL, Bouzat P, Buki A, Ceresoli M, Chesnut RM, Chiara O, Citerio G, Coccolini F, Coimbra R, di Saverio S, Fraga GP, Gupta D, Helbok R, Hutchinson PJ, Kirkpatrick AW, Kinoshita T, Kluger Y, Leppaniemi A, Maas AIR, Maier RV, Minardi F, Moore EE, Myburgh JA, Okonkwo DO, Otomo Y, Rizoli S, Rubiano AM, Sahuquillo J, Sartelli M, Scalea TM, Servadei F, Stahel PF, Stocchetti N, Taccone FS, Tonetti T, Velmahos G, Weber D, Catena F (2019) WSES consensus conference guidelines: monitoring and management of severe adult traumatic brain injury patients with polytrauma in the first 24 hours. World J Emerg Surg 14:53. Published 2019 Nov 29. https://doi.org/10.1186/s13017-019-02701

18. Saltzherr TP, Bakker FC, Beenen LF, Dijkgraaf MGW, Reitsma JB, Goslings JC, REACT Study Group (2012) Randomized clinical trial comparing the effect of computed tomography in the trauma room versus the radiology department on injury outcomes. Br J Surg 99(Suppl 1):105-113. https://doi.org/10.1002/bjs.7705

19. Steyerberg EW, Wiegers E, Sewalt C, Buki A, Citerio G, De Keyser Vet al. (2019) Case-mix, care pathways, and outcomes in patients with traumatic brain injury in CENTER-TBI: a European prospective, multicenter, longitudinal, cohort study. Lancet Neurol 18(10):923-934. https://doi.org/10.1016/S1474-4422(19)30232-7

20. Wulffeld S, Rasmussen LS, Højlund Bech B, Steinmetz J (2017) The effect of CT scanners in the trauma room - an observational study. Acta Anaesthesiol Scand 61:832-840. https://doi.org/10. 1111/aas. 12927

Publisher's note Springer Nature remains neutral with regard to jurisdictional claims in published maps and institutional affiliations. 